\title{
REDOX regulation of early embryo development
}

\author{
Alexandra J. Harvey, Karen L. Kind and Jeremy G. Thompson* \\ Reproductive Medicine Unit, Department of Obstetrics and Gynaecology, Adelaide \\ University, The Queen Elizabeth Hospital, Woodville Road, Woodville SA 5011, Australia
}

\begin{abstract}
Preimplantation embryonic development is associated with a change in preference in energy metabolism pathways. Although oxidative phosphorylation is obligatory in most species throughout preimplantation development, an increasing role for energy derived from glycolysis is associated with compaction and blastulation. Such a shift in metabolic pathway preference is desirable as the embryo faces an increasingly hypoxic environment in utero. We hypothesize that this shift in metabolic preference is associated with a change in the reduction-oxidation (REDOX) state within the embryo, affecting not only the energy production required for development, but also the activity of REDOX-sensitive transcription factors, which may alter gene expression patterns. Shifts in intracellular REDOX state may also contribute to spatial differences in cell activity, especially after compaction, and perhaps even major embryonic events such as fertilization, genome activation and cellular differentiation.
\end{abstract}

Early embryo development requires energy (that is, the formation of adenosine triphosphate, ATP), which is produced through two possible mechanisms: glycolysis, using glucose as a substrate, and oxidative phosphorylation, using pyruvate or oxaloacetate as a substrate. The pioneering work of Brinster, Biggers, Whitten, Whittingham and Wales from the late 1950 s to the early 1970 s revealed that for mouse embryo development to the blastocyst stage, pyruvate or oxaloacetate are essential for early cleavage, but that glucose is an effective substrate from the eight-cell stage (Bavister, 1995; Wales, 1975). These studies were the first to reveal that a change in metabolic state is involved in the control of early development and led many other workers to examine the concentrations of exogenous energy substrates required for optimal ex vivo embryo development (Bavister, 1995).

Another key energy substrate (although usually not considered as such) is oxygen (Fig. 1). Oxygen is essential for the conversion of ADP to ATP in oxidative phosphorylation through its role as an electron acceptor in the electron transport chain. However, the use of oxygen as an energy substrate also results in the production of reactive oxygen species (ROS), particularly the superoxide anion $\left(\mathrm{O}_{2}^{-\bullet}\right)$ and the hydroxyl radical $\left(\mathrm{OH}^{\circ}\right)$. ROS are highly active electron acceptors, able to strip electrons from other molecules that, in turn, become free radicals. Hydrogen peroxide $\left(\mathrm{H}_{2} \mathrm{O}_{2}\right)$ is not a radical per se, but is a product of $\mathrm{O}_{2}-\bullet$ and metal ion catalysis. However, both $\mathrm{H}_{2} \mathrm{O}_{2}$ and $\mathrm{O}_{2}{ }^{-}$can form the extremely reactive $\mathrm{OH}^{\bullet}$. The over-generation of intracellular ROS during culture of mammalian embryos in vitro is generally thought to be detrimental to embryo development (reviewed by Johnson and Nasr-Esfahani, 1994; Guerin

*Correspondence

Email: jeremy.thompson@adelaide.edu.au et al., 2001). The consensus view is that 'over-production' of ROS is unfavourable for embryo development, coincident with perturbed metabolic activity. We believe this to be an overly simplistic view and prefer to think in terms of altered reduction-oxidation (REDOX) states, in which a prolonged oxidized state within the embryo, especially after early cleavage, is not favourable for embryo development. Other in vitro culture conditions may also shift the REDOX state unfavourably. Furthermore, there are some specific events in development that appear to be associated with a change in the REDOX state, indicating that REDOX state has a causative role. These events include sperm-mediated oocyte activation, embryonic genome activation and embryonic hatching from the zona pellucida.

\section{Intracellular reduction-oxidation states}

The intracellular REDOX state describes a complex interaction of the relative concentrations of reduced and oxidized forms of a variety of molecules, including the nicotinamide adenine nucleotides $\left(\mathrm{NAD}(\mathrm{P})^{+} / \mathrm{NAD}(\mathrm{P}) \mathrm{H}\right)$, flavins $\left(\mathrm{FAD}^{+} / \mathrm{FADH}\right)$, ubiquinones, peroxides and thiols-disulphides (for example, glutathione (GSH/GSSG)), and others (Fig. 1). Estimation of the REDOX state is difficult to measure with accuracy, and is usually achieved by direct or indirect measurement of REDOX molecules, such as intracellular glutathione or peroxides, [NAD+]/[NADH] or [pyruvate]/[lactate].

REDOX state is also significantly influenced by factors that stimulate the generation or neutralization of intracellular ROS. ROS are produced primarily through electron transport at the inner mitochondrial membrane, but also by cytoplasmic or membrane-bound NADPH-oxidase, cytochrome p450 enzymes and the xanthine-xanthine oxidase systems (Gilbert and Colton, 1999). Mammalian cells have 


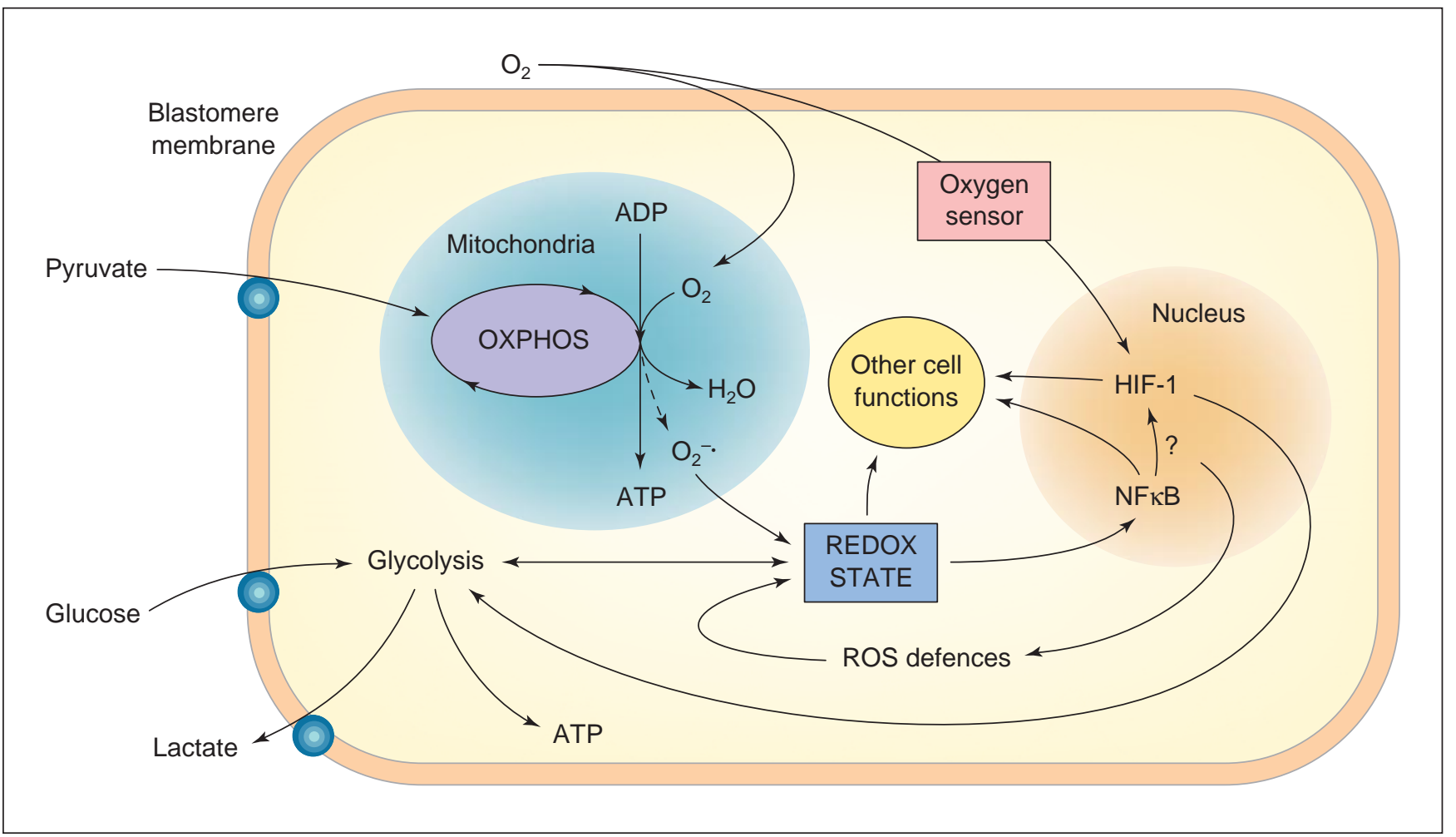

Fig. 1. REDOX regulation of early embryo development incorporating oxygen as a key modulator of ATP production via metabolic pathways (oxidative phosphorylation (OXPHOS) and glycolysis) and REDOX state. A consequence of $\mathrm{OXPHOS}_{\text {is }}$ production of $\mathrm{O}_{2}{ }^{-}$, the amount of which significantly affects the REDOX state by the interaction with REDOX-cycling molecules such as the nicotinamide adenine nucleotides (NAD(P)+/NAD(P)H) and glutathione (GSH/GSSG). Glycolytic pathway activity is affected by both oxygen availability (through the stabilization of hypoxia-inducible factor 1 (HIF-1), which is regulated by the oxygen sensor and subsequent gene expression) and indirectly through the REDOX state (via the influence of availability of $N A D(P)+/ N A D(P) H)$. Other cellular functions, such as apoptosis and cell cycle control, are also significantly influenced by oxygen availability and REDOX state, via transcription factors such as nuclear factor kappaB (NFKB). ROS: reactive oxygen species.

several mechanisms to protect against the generation of ROS. Several enzymes catalyse their destruction, including $\mathrm{Cu}-\mathrm{Zn}$ and Mn-superoxide dismutases, catalase and glutathione peroxidase, some of which are known to be transcribed in preimplantation mammalian embryos (Harvey et al., 1995). Many compounds have antioxidant activity and act as electron donors for oxidant species and either yield inactive molecules themselves (such as thiols forming disulphides) or are sufficiently stable as radicals to be virtually non-reactive (for example, $\alpha$-tocopherol). However, ROS present a paradox in that they may act as second messengers in mammalian cells (Schreck and Baeuerle, 1991; Wenger, 2000). Several genes are activated in response to alterations in ROS concentration including those for protein kinases (Burdon, 1996), tyrosine kinases and growth factors (Nose, 2000). The interaction of cytokines and growth factors with cell receptors has been shown to elicit increases in ROS production (Nose, 2000). However, it is most likely that the balance between ROS production and elimination (that is, the REDOX state), rather than ROS themselves, determines these responses.
Therefore, REDOX state regulation has important functions for optimal growth responses (Burdon, 1996).

\section{Environment of the reproductive tract}

After ovulation, fertilization, and early embryo development in the oviduct, embryos migrate to the uterus, where implantation occurs. The timing of implantation relative to the development of the embryo differs among species. Despite these differences, the timing of the transition from oviduct to uterus for most species occurs around the time of compaction and blastulation (Boyd and Hamilton, 1952), indicating that the oviduct is excluded physiologically as a site for significant post-hatching development.

Oviductal $\mathrm{O}_{2}$ concentration is about $40 \%$ or less than atmospheric concentration (Leese, 1995) and it appears that the uterine environment has an even lower $\mathrm{O}_{2}$ concentration than that of the oviduct (Fischer and Bavister, 1993). Thus embryos encounter a decreasing $\mathrm{O}_{2}$ concentration gradient as they progress down the reproductive tract. Furthermore, during early implantation, hypoxic and even anoxic 
conditions confront the invading trophectoderm (reviewed by Leese, 1995). In addition, fluid compositional studies have established that oviductal fluid generally has relatively low glucose concentrations $\left(<1 \mathrm{mmol} \mathrm{I}^{-1}\right)$ compared with those in uterine fluid, indicating an environment more favourable for glycolytic activity in the uterus.

\section{Metabolic evidence for REDOX regulation of embryo development}

Energy (ATP) production increases at the onset of compaction and blastocyst development to support increased protein synthesis and activity of ion-transport systems, notably the $\mathrm{Na}^{+} / \mathrm{K}^{+}$-dependent ATPase (Wales, 1975; Leese, 1995). An increase in ATP production is inferred from the increases in uptake of oxygen and energy substrates, such as pyruvate and glucose (Houghton et al., 1996; Thompson et al., 1996). Furthermore, measurements of ATP:ADP ratios imply that demand for ATP increases after major activation of the embryonic genome (Rozell et al., 1992). The increase in glucose uptake and metabolism from compaction appears to be a common phenomenon for embryos across a range of species. This increase has been attributed to increased glycolytic enzyme activity (Houghton et al., 1996) and increased capacity for glucose uptake by facilitated transporters (Pantaleon and Kaye, 1998). During development to the blastocyst stage, there is a significant shift from a dependence on ATP generation by oxidative phosphorylation to a dependence on ATP generation by glycolysis. In particular, glycolytic activity leading to lactate production accounts for all glucose uptake in post-compaction stage embryos of several species including rats (Brison and Leese, 1991), sheep (Gardner et al., 1993), cows (Thompson et al., 1996) and humans (Gott et al., 1990). Collectively, these data can be interpreted as signifying that post-compaction development is associated with a significant shift in the REDOX state to a more reduced state, favoured by postcompaction embryos to accommodate an increasingly hypoxic environment. This is not to say that oxidative phosphorylation is not important during post-compaction development. Indeed, mouse blastocysts that have a reduced capacity for oxidizing substrates via the Krebs cycle (that is, they convert $100 \%$ glucose to lactate) are associated with poor post-transfer development (Lane and Gardner, 1998).

\section{Manipulation of substrates and metabolic pathways during development in vitro}

Studies using inhibitors of oxidative phosphorylation have revealed significant differences in developmental ability, dependent on whether treatment is applied before or after compaction. Rat (Brison and Leese, 1994), cattle (Thompson et al., 2000) and pig (Macháty et al., 2001) embryos continue development after compaction when oxidative phosphorylation is either partly or completely inhibited. In contrast, application of inhibitors during precompaction development is highly inhibitory to development
(Thomson, 1967; Brison and Leese, 1994; Thompson et al. 2000).

However, compounds that either suppress glycolysis, such as ethylene diamine tetra-acetic acid (Gardner and Lane, 1996), or stimulate the tricarboxylic acid (TCA) cycle, such as 2-dichloroacetic acid (Penzias et al., 1993), during pre-compaction development, have been found to improve development.

Decreasing the $\mathrm{O}_{2}$ concentration within the incubation atmosphere from atmospheric to more physiological concentrations during culture in vitro is beneficial for mammalian embryo development (for examples, see Thompson et al., 1990; Li and Foote, 1993; Dumoulin et al., 1999). Both the number of cells and the proportion of embryos developing to the blastocyst stage increase when oxygen concentrations during incubation are in the 5-7\% range. Furthermore, metabolic activity of embryos cultured under decreased $\mathrm{O}_{2}$ tension correlates more closely with that of in vivo recovered embryos (Hooper et al., 2001). These results have largely been interpreted in terms of reduced $\mathrm{O}_{2}$ tension decreasing the production of ROS within the embryo. However, this conclusion is based on little direct evidence. Fluorescence of the intracellular peroxide sensor, dichlorodihyarofluorescein diacetate (DCHFDA), was not correlated with $\mathrm{O}_{2}$ concentrations during incubation in one study (Nasr-Esfahani et al., 1992) but was in another (Goto et al., 1993). In addition, reducing $\mathrm{O}_{2}$ tension is more effective in promoting embryo development in vitro than is treatment with detoxifying enzymes (superoxide dismutase (SOD) and catalase) (Orsi and Leese, 2001). Furthermore, restricting $\mathrm{O}_{2}$ availability after compaction by further reducing the $\mathrm{O}_{2}$ tension from 7 to $2 \%$ is beneficial for bovine embryo development after compaction (Thompson et al., 2000). More convincingly, incubation in 5\% $\mathrm{O}_{2}$ compared with $20 \% \mathrm{O}_{2}$ increases oxygen uptake and pyruvate oxidation (Hooper et al., 2001). This finding is significant as the effect of a reduction in $\mathrm{O}_{2}$ tension from atmospheric levels to $5 \%$ within embryos has also been examined using a mathematical model (Byatt-Smith et al., 1991). Byatt-Smith et al. (1991) showed that for small mammalian embryos, such as mouse embyros, $\mathrm{O}_{2}$ from a $5 \%$ atmosphere would be able to sustain oxidative phosphorylation throughout development, albeit under hypoxic conditions. However, larger embryos, such as human or cattle embryos, would establish a significant gradient leading to anoxia in the centre of the embryo, which may explain some of the metabolic differences among embryos of different species. Such a gradient, especially during compaction, may also provide spatial information to cells within the embryo (Fig. 2). This prediction is supported by the observation that the metabolic profile of inner cell mass cells differs from that of trophectoderm (Hewitson and Leese, 1993).

\section{Intracellular NAD+/NADH during embryo development}

Mouse embryos contain concentrations of $\mathrm{NAD}^{+}$and $\mathrm{NADH}$ of 0.25 and $0.85 \mathrm{mmol} \mathrm{kg}^{-1}$, respectively, similar 


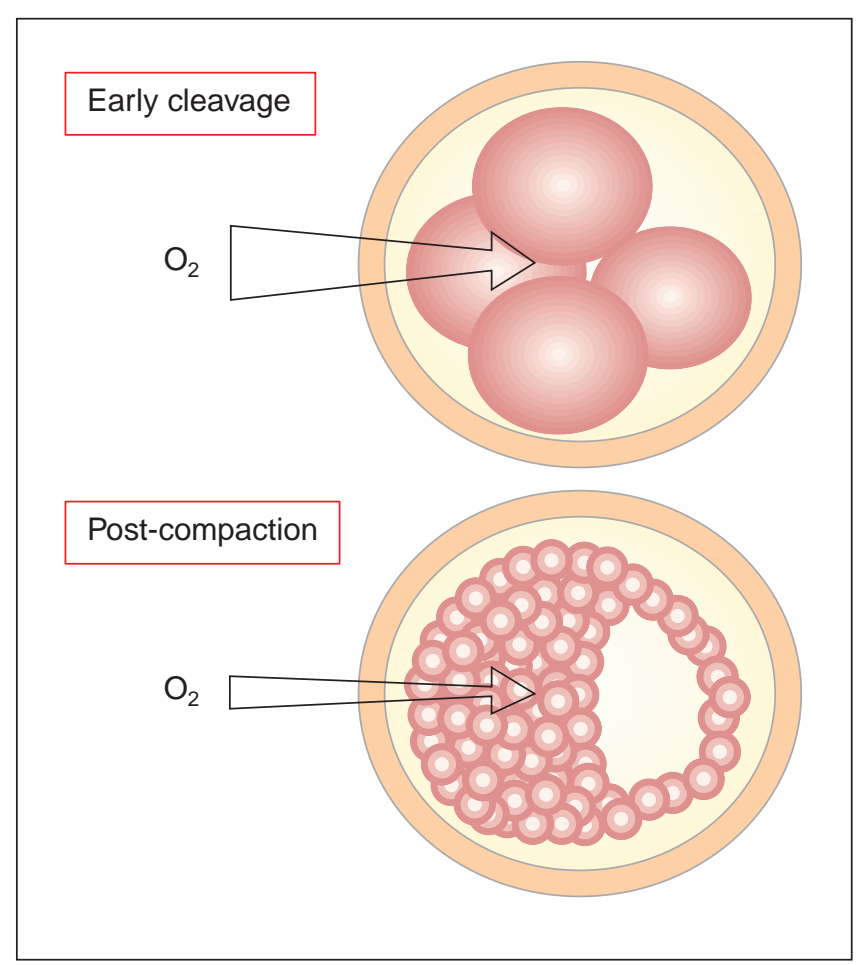

Fig. 2. Hypothetical model of $\mathrm{O}_{2}$ gradient in early cleavage and post-compaction stage embryos during development in vivo. Early cleavage stage embryos encounter a physiological $\mathrm{O}_{2}$ concentration during transport through the oviduct, where a minimal gradient is encountered by individual blastomeres. However, postcompaction stage embryos encounter a significantly lower (hypoxic) $\mathrm{O}_{2}$ environment in utero, potentially creating a more marked gradient within the embryo and resulting in the establishment of spatial relationships between blastomeres.

concentrations to those in adult tissues (Wales, 1975). The intracellular ratio of [NAD+]:[NADH] does not vary greatly with embryonic stage; however, this finding does not account for possible variations within mitochondrial and cytoplasmic pools (Wales, 1975), which would be influenced by concentrations of [pyruvate]:[lactate] in the cytosol. However, considerable variation occurs among individual embryos at either the one- or two-cell stage (Wales, 1975). Blastocyst development from the two-cell stage is significantly affected by the relative concentration of pyruvate and lactate in the medium, which is postulated to affect intracellular [pyruvate]:[lactate], with an optimum ratio of approximately 1:10 of pyruvate:D,L-lactate.

\section{Intracellular glutathione and NADP+/NADPH during embryo development}

Glutathione, a tripeptide of glycine, cysteine and glutamine, is an important regulator of REDOX status (Munday and Winterbourn, 1989; Fig. 3) and has been detected in reproductive tract fluid (Gardiner et al., 1998). Glutathione plays a major role in regulating ROS concentrations within the cytoplasm, both directly as a free-radical scavenger, and as a substrate with NADPH for detoxifying ROS using GSH peroxidase (Guerin et al., 2001). Glutathione concentrations measured throughout preimplantation embryo development decrease as early cleavage proceeds (Gardiner and Reed, 1995). Preimplantation stage embryos have little capacity for GSH synthesis (Gardiner and Reed, 1995). However, increasing intracellular concentrations of reduced glutathione, especially during oocyte maturation, are associated with both improved fertilization and subsequent embryo development in vitro (Abeydeera et al., 1999; de Matos and Furnus, 2000). Appropriate GSH status is also usually achieved by the inclusion of its constituent amino acids, cysteine, glycine and glutamine, within the incubation medium.

Pronuclear formation after fertilization in mice is also accompanied by increased glycolysis and glucose oxidation through the pentose phosphate cycle, with no change in pyruvate or glutamine entry into the TCA cycle (Pantaleon et al., 2001). This is a sperm-mediated effect, as parthenogenesis does not affect metabolism whereas the degree of polyspermy influences metabolic rate (Pantaleon et al., 2001). As the pentose cycle regulates concentrations of $\mathrm{NADPH}$ (Fig. 3), such activity may alter [NADP+]:[NADPH]. Similarly, a cell cycle-linked REDOX mechanism (experimentally mediated through addition of thioredoxin) has been implicated in the cessation of sperm-mediated $\mathrm{Ca}^{2+}$ spiking after fertilization (Day et al., 2000).

\section{Periods of ROS production or extinction during embryo development}

The effect of ROS on embryo development is paradoxical. Most studies have shown that prolonged, experimentally induced ROS production severely inhibits embryo development (Johnson and Nasr-Esfahani, 1994; Guerin et al., 2001). Controversially, the inclusion of antioxidants or radical-detoxifying enzymes to embryo culture medium produces a varied response (Noda et al., 1991; Payne et al., 1992; Orsi and Leese, 2001). Hydrogen peroxide concentrations increase during the two-four-cell transition period, at about the time of embryonic genome activation, in mouse embryos cultured in vitro, but not in those developed in vivo (Nasr-Esfahani et al., 1990). This finding indicates that an increase in ROS may be associated with the arrest of development at the two-cell stage, observed under some in vitro culture conditions. However, increases in $\mathrm{H}_{2} \mathrm{O}_{2}$ concentrations in vitro were also observed in embryos from a strain of mice that develop successfully in vitro. A very brief pulse of $\mathrm{H}_{2} \mathrm{O}_{2}$ delivered to bovine embryos at the eightcell stage, the developmental stage at which major activation of the embryonic genome occurs in cattle, had a positive (although not significant) influence on their capacity to develop to the blastocyst stage (Morales et al., 1999). Treatments administered at other stages of development inhibited development. Similarly, mouse embryo hatching, in embryos derived both in vivo and in vitro, has also been associated with a specific burst of ROS production (Thomas 


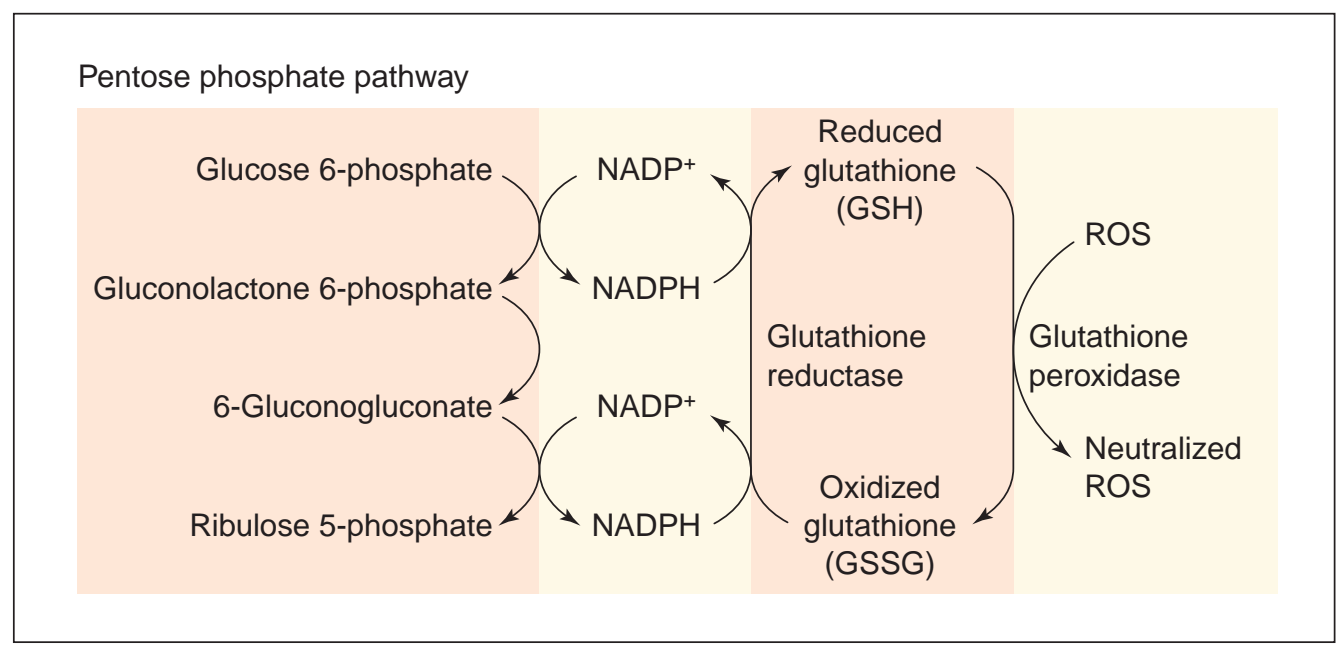

Fig. 3. Relationship between the pentose phosphate pathway (PPP), reactive oxygen species (ROS) and glutathione (GSH) REDOX status.

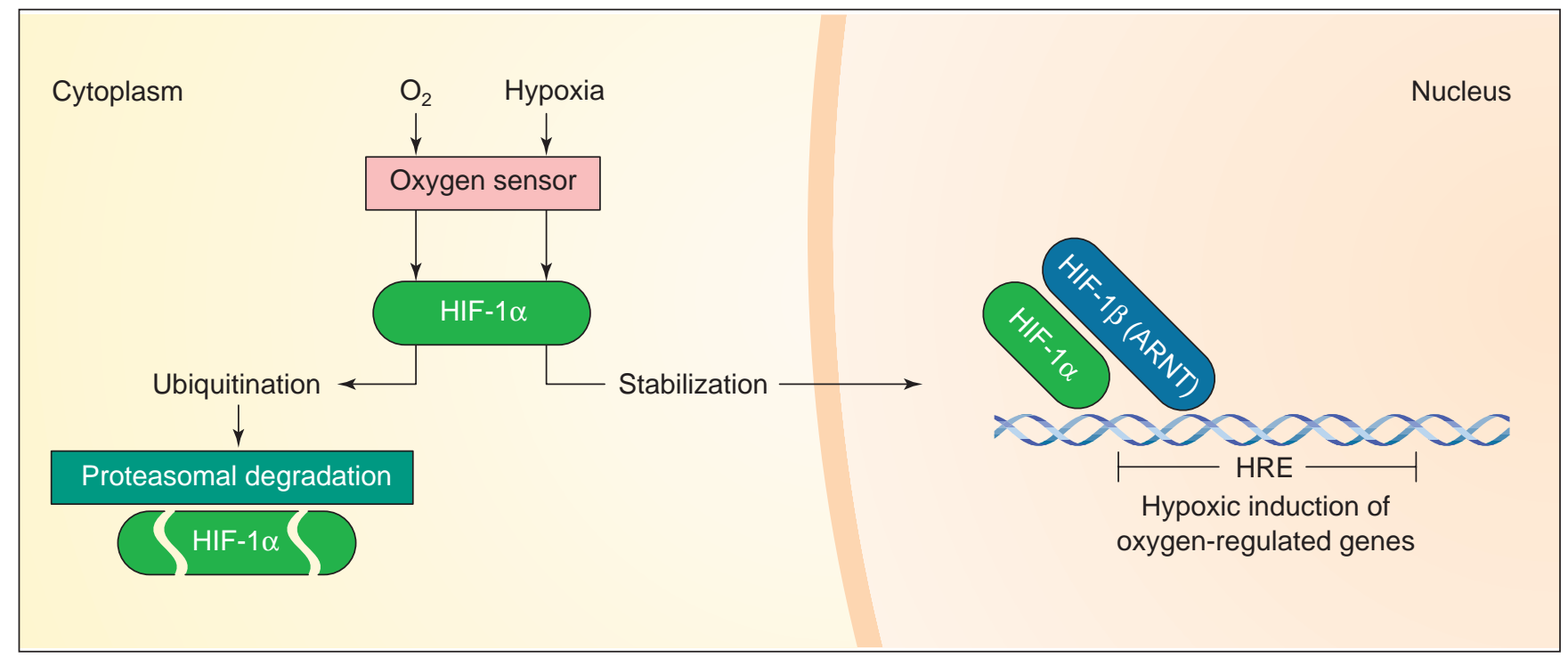

Fig. 4. Hypoxic regulation of hypoxia inducible factor (HIF-1) protein stabilization and DNA binding. Changes in oxygen are detected through a putative oxygen sensor. Under normoxic conditions, HIF-1 $\alpha$ is ubiquinated and undergoes proteasomal degradation. Conversely, under hypoxic conditions, HIF- $1 \alpha$ is stabilized enabling translocation to the nucleus where it dimerizes with the $\beta$ subunit (aryl hydrocarbon receptor nuclear translocator (ARNT)) to form the active DNA binding complex, which binds to the hypoxia response element (HRE) in target genes. In the preimplantation embryo, induction of HIF activity is a potential mechanism through which responses to changes in oxygen concentration, including alterations in metabolism and gene expression, may be mediated.

et al., 1997). The production of ROS may also be an important regulatory system for programmed cell death (apoptosis) in the blastocyst (Pierce et al., 1991).

\section{Transcription factors mediated by the REDOX state}

Can a change in metabolic activity during early embryo development elicit a molecular response? As mentioned earlier, a number of genes are known to be responsive to a change in REDOX state. Such transcriptional control is mediated largely by transcription factors sensitive to the intracellular REDOX state and several such factors may be involved in embryo development. Members of the hypoxia inducible factor family of transcription factors are influenced directly by the intracellular oxygen concentration, and may be important for embryonic development within 
the hypoxic reproductive tract, whereas nuclear factor kappa $\beta$ may be involved in stress-related and maternal recognition (cytokine) responses.

\section{Hypoxia inducible factor family}

Hypoxia inducible factors (HIFs) are basic helix-loophelix Per-ARNT-Sim (bHLH-PAS) transcription factors that mediate oxygen-dependent expression of a range of genes involved in cellular and systemic processes (Fig. 4), including angiogenesis, erythropoiesis, glucose transport and glycolysis (reviewed in Semenza, 1999, 2000; Wenger and Gassman, 1999; Wenger, 2000). HIF-1, the first HIF to be identified, is a heterodimer composed of HIF- $1 \alpha$ and HIF-1 $\beta$ subunits. HIF- $1 \alpha$ was identified as a novel protein, whereas the HIF-1 $\beta$ subunit is identical to the aryl hydrocarbon receptor nuclear translocator (ARNT). HIF-1 $\alpha$ protein concentrations are regulated precisely according to cellular oxygen concentration. More recently, other similar hypoxia responsive bHLH-PAS proteins, HIF- $2 \alpha$ and HIF-3 $\alpha$, have also been identified.

Regulation of HIF-1 activity can occur at a number of levels, including mRNA expression, nuclear localization and transcriptional activation, and changes in the protein stability of HIF- $1 \alpha$ appear to be the principal control mechanism (reviewed in Semenza, 1999, 2000; Wenger and Gassman, 1999; Fig. 4). Under normoxic conditions, HIF$1 \alpha$ protein is degraded rapidly by the ubiquitin-proteasome system. This process is mediated through binding of the von Hippel-Lindau ( $\mathrm{pVHL}$ ) tumour suppressor protein to HIF-1 $\alpha$. Multiple mechanisms have been proposed to account for the nature of the oxygen sensor that detects changes in oxygen concentration (Semenza, 1999; Wenger and Gassman, 1999). A study by Jaakkola et al. (2001) indicates that the binding of $\mathrm{pVHL}$ to HIF-1 $\alpha$ is promoted through oxygen-regulated hydroxylation of a proline residue in HIF- $1 \alpha$. Under hypoxic conditions, the HIF- $1 \alpha$ protein is not targeted for degradation and can translocate to the nucleus to dimerize with the $\beta$ subunit, thus forming the active DNA-binding complex. HIF-1 can activate the expression of a number of genes involved in the adaptation to low oxygen, including erythropoietin, vascular endothelial growth factor, inducible nitric oxide synthase, haem oxygenase 1, glucose transporter 1 and several glycolytic enzymes (Wenger and Gassman, 1999; Semenza, 1999, 2000). Many of these genes are known to play important roles during late preimplantation development and early placentation.

The involvement of HIF in embryonic development has been demonstrated by the production of gene knockout mice. Homozygote hif- $1 \alpha^{-/-}$mice die around embryonic day 10.5-11.0 and exhibit neural tube defects, cardiovascular malformations, cell death within the cephalic mesenchyme and impaired vascularization (lyer et al., 1998, Kotch et al., 1999). Similarly, hif-1 $\beta$ knockout mice die at midgestation, with primary defects including defective yolk sac angiogenesis and compromised fetal capillary develop- ment (Maltepe et al., 1997) or failure of the embryonic part of the placenta to vascularize and form the labryinthine spongiotrophoblast (Kozak et al., 1997). Mice lacking HIF$2 \alpha$ also die between embryonic day 12.5 and embryonic day 16.5 , primarily as a result of defects in catecholamine synthesis (Tian et al., 1998).

Preliminary data indicate a differential pattern of expression of HIF-1 $\alpha$ in mouse embryos derived in vivo and bovine embryos derived in vitro (Harvey et al., 2001, 2002). HIF-2 $\alpha$ mRNA has also been observed in cultured bovine blastocysts (Harvey et al., 2001). HIF-1 $\beta$ (ARNT) mRNA has been detected in rabbit morulae and blastocysts derived in vivo (Tscheudschilsuren et al., 1999). Nevertheless, further studies are required to determine whether HIF- $1 \alpha$ or HIF-2 $\alpha$ protein nuclear translocation and DNA binding are responsive to hypoxic conditions in the preimplantation embryo.

\section{Nuclear factor kappaB}

The transcription factor nuclear factor kappaB (NFкB) has key roles in the regulation of cell proliferation and programmed cell death, as well as in immune, inflammatory and stress responses, and controls numerous genes, including those involved in cell adhesion and the cell cycle (JanssenHeininger et al., 2000). NFאB consists of two subunits and is normally sequestered in the cytoplasm through its association with the inhibitory molecule IkappaB (IкB) (Mercurio and Manning, 1999). NFKB can be activated by a variety of stimuli associated with stress, and potentially that encountered during culture in vitro. Potent inducers include the cytokines tumour necrosis factor $\alpha$ (TNF- $\alpha$ ) and interleukin$1 \beta$ (IL-1 $\beta$ ). ROS have been shown to be involved in NFKB activation through REDOX mechanisms in many, but not all, cell lines (Meyer et al., 1994; Brennan and O'Neill, 1995). NFאB has also been shown to be induced by hypoxia (Koong et al., 1994). In addition to investigations showing knockout embryo lethality, recent evidence documents the expression and distribution of $\mathrm{NF} \kappa \mathrm{B}$ during preimplantation embryo development in mice (Parrott and Gay, 1998; Nishikimi et al., 1999). The expression of NFKB subunits during embryo development may be required for responses to environmental stimuli such as stress (Parrot and Gay, 1998). It has been suggested that activation of NFKB at the early one-cell stage is required for the development of mouse embryos beyond the two-cell stage (Parrot and Gay, 1998).

\section{Other REDOX-sensitive transcription factors}

Activator protein-1 (AP-1) and p53 are other transcription factors that are REDOX-regulated (Yao et al., 1994; Giaccia and Kastan, 1998). AP-1 is a heterodimer of c-fos and c-jun proteins and tends to elicit opposing effects to those elicited by NFKB. It is unclear whether AP-1 protein is present in the mammalian embryo; indeed, c-fos and c-jun proteins were not detectable in the early cleaving mouse embryo (Ahmad and Naz, 1993). The tumour-suppressor 
protein p53, which is known to regulate apoptosis, interacts with HIF- $1 \alpha$, providing an alternative protein stabilization pathway (Carmeliet et al., 1998). Moley and Mueckler (2000) have suggested that hyperglycaemic-induced apoptosis in mouse embryos is mediated through HIF- $1 \alpha$ stabilization with p53.

\section{Concluding remarks}

Many studies have examined the effect of medium composition, in particular energy substrate concentrations, on embryo development up to the blastocyst stage as the end-point. Few of these studies examine the mechanism by which substrate concentrations and culture conditions affect development. We propose here that one mechanism that should receive close attention is alteration of the intracellular REDOX state. A perturbed REDOX state, as a consequence of sub-optimal culture conditions, may not only alter ATP production, but also gene expression patterns during development, leading to altered placental and fetal growth patterns.

The authors would like to thank Professor Henry Leese, University of York, for his support and valuable input to this review. Supported by the National Health and Medical Research Council Project Grant 157941. A. J. Harvey was supported by NWAHS.

\section{References}

Key references are identified by asterisks.

Abeydeera LR, Wang W-H, Cantley TC, Prather RS and Day BN (1999) Glutathione content and embryo development after in vitro fertilisation of pig oocytes matured in the presence of a thiol compound and various concentrations of cysteine Zygote 7 203-210

Ahmad K and Naz RK (1993) Presence and possible role of c-ras and nuclear (c-fos and c-jun) proto-oncogene products in preimplantation embryonic development in mice Molecular Reproduction and Development 36 297-306

*Bavister BD (1995) Culture of preimplantation embryos: facts and artifacts Human Reproduction Update 191-148

Boyd JD and Hamilton WJ (1952) Cleavage, early development and implantation of the egg. In Marshall's Physiology of Reproduction pp 1-124 (Vol II) Ed. AS Parkes. Longmans, Green and Co., London

Brennan P and $\mathbf{O}^{\prime}$ Neill AJ (1995) Effects of oxidants and antioxidants on nuclear factor $\mathrm{\kappa B}$ activation in three different cell lines: evidence against a universal hypothesis involving oxygen radicals Biochimica et Biophysica Acta 1260 167-175

Brison DR and Leese HJ (1991) Energy metabolism in late preimplantation rat embryos Journal of Reproduction and Fertility 93 245-251

Brison DR and Leese HJ (1994) Blastocoel cavity formation by preimplantation rat embryos in the presence of cyanide and other inhibitors of oxidative phosphorylation Journal of Reproduction and Fertility 101 305-309

*Burdon RH (1996) Control of cell proliferation by reactive oxygen species Biochemical Society Transactions 24 1028-1032

Byatt-Smith JG, Leese HJ and Gosden RG (1991) An investigation by mathematical modelling of whether mouse and human preimplantation embryos in static culture can satisfy their demands for oxygen by diffusion Human Reproduction 6 52-57

Carmeliet P, Dor Y, Herbert JM et al. (1998) Role of HIF-1 $\alpha$ in hypoxiamediated apoptosis, cell proliferation and tumor angiogenesis Nature $394485-490$
Day ML, McGuinness OM, Berridge MJ and Johnson MH (2000) Regulation of fertilization-induced $\mathrm{Ca}^{2+}$ spiking in the mouse zygote Cell Calcium 28 47-54

de Matos DG and Furnus CC (2000) The importance of having high glutathione (GSH) level after bovine in vitro maturation on embryo development: effect of $\beta$-mercaptoethanol, cysteine and cystine Theriogenology 53 761-771

Dumoulin JCM, Meijers CJ, Bras M, Coonen E, Geraedts JP and Evers JL (1999) Effect of oxygen concentration on human in vitro fertilization and embryo culture Human Reproduction 14 465-469

Fischer B and Bavister BD (1993) Oxygen tension in the oviduct and uterus of rhesus monkeys, hamsters and rabbits Journal of Reproduction and Fertility 99 673-679

Gardiner CS and Reed DJ (1995) Synthesis of glutathione in the preimplantation mouse embryo Archives of Biochemistry and Biophysics 318 30-36

Gardiner CS, Salmen JJ, Brandt CJ and Stover SK (1998) Glutathione is present in reproductive tract secretions and improves development of mouse embryos after chemically induced glutathione depletion Biology of Reproduction $\mathbf{5 9}$ 431-436

Gardner DK and Lane M (1996) Alleviation of the '2-cell block' and development to the blastocyst of CF-1 mouse embryos: role of amino acids, EDTA and physical parameters Human Reproduction 11 2703-2712

Gardner DK, Lane M and Batt P (1993) Uptake and metabolism of pyruvate and glucose by individual sheep preattachment embryos developed in vivo. Molecular Reproduction and Development 36 313-319

Giaccia AJ and Kastan MB (1998) The complexity of p53 modulation: emerging patterns from divergent signals Genes and Development 12 2973-2983

Gilbert DL and Colton CA (1999) An overview of reactive oxygen species. In Reactive Oxygen Species in Biological Systems: An Interdisciplinary Approach pp 679-695 Eds DL Gilbert and CA Colton. Kluwer Academic-Plenum Publishers, New York

Goto Y, Noda Y, Mori T and Nakano M (1993) Increased generation of reactive oxygen species in embryos cultured in vitro. Free Radicals in Biology and Medicine 15 69-75

Gott AL, Hardy K, Winston RML and Leese HJ (1990) Non-invasive measurement of pyruvate and glucose uptake and lactate production by single human preimplantation embryos Human Reproduction $\mathbf{5}$ 104-108

*Guerin P, El Mouatassim S and Menezo Y (2001) Oxidative stress and protection against reactive oxygen species in the pre-implantation embryo and its surrounding Human Reproduciton Update 7 175-189

Harvey AJ, Ritter LJ and Thompson JG (2001) Expression of hypoxiainducible factor- 1 and $-2 \alpha$ during bovine preimplantation embryo development Proceedings of the Society for Reproductive Biology 3268

Harvey AJ, Collett RA, Kind KL and Thompson JG (2002) Expression of hypoxia-inducible factor- $1 \alpha$ during mouse preimplantation embryo development Theriogenology 57496 (Abstract)

Harvey MB, Arcellana-Panlilio MY, Zhang X, Schultz GA and Watson AJ (1995) Expression of genes encoding antioxidant enzymes in preimplantaion mouse and cow embryos and primary bovine oviduct cultures employed for embryo coculture Biology of Reproduction 53 $532-540$

Hewitson LC and Leese HJ (1993) Energy metabolism of the trophectoderm and inner cell mass of the mouse blastocyst Journal of Experimental Zoology 267 337-343

Hooper K, Lane M and Gardner DK (2001) Reduced oxygen concentration increases mouse embryo development and oxidative metabolism Theriogenology 55334

Houghton FD, Thompson JG, Kennedy CJ and Leese HJ (1996) Oxygen consumption and energy metabolism of the early mouse embryo Molecular Reproduction and Development 44 476-485

Iyer NV, Kotch LE, Agani F et al. (1998) Cellular and developmental control of $\mathrm{O}_{2}$ homeostasis by hypoxia-inducible factor $1 \alpha$ Genes and Development 12 149-162

Jaakola P, Mole DR, Tian YM et al. (2001) Targeting of HIF- $\alpha$ to the von Hippel-Lindau ubiquitylation complex by $\mathrm{O}_{2}$-regulated prolyl hydroxylation Science $292468-472$ 
Janssen-Heininger YM, Poynter ME and Baeuerle PA (2000) Recent advances towards understanding redox mechanisms in the activation of nuclear factor $\kappa$ B Free Radical Biology and Medicine 28 1317-1327

Johnson MH and Nasr-Esfahani MH (1994) Radical solutions to cultural problems: could free oxygen radicals be responsible for the impaired development of preimplantation mammalian embryos in vitro? Bioessays 16 31-38

Koong AC, Chen EY and Giaccia AJ (1994) Hypoxia causes the activation of nuclear factor kappaB through the phosphorylation of I kappaB alpha on tyrosine residues Cancer Research 54 1425-1430

Kotch LE, lyer NV, Laughner E and Semenza GL (1999) Defective vascularization of HIF-1 $\alpha$-null embryos is not associated with VEGF deficiency but with mesenchymal cell death Developmental Biology 209 $254-267$

Kozak KR, Abbott B and Hankinson O (1997) ARNT-deficient mice and placental differentiation Developmental Biology 191 297-305

Lane M and Gardner DK (1998) Amino acids and vitamins prevent cultureinduced metabolic perturbations and associated loss of viability of mouse blastocysts Human Reproduction 13 991-997

*Leese HJ (1995) Metabolic control during preimplantation mammalian development Human Reproduction Update 1 63-72

Li J and Foote RH (1993) Culture of rabbit zygotes into blastocysts in protein free medium with one to twenty per cent oxygen Journal of Reproduction and Fertility 98 163-167

Macháty Z, Thompson JG, Abeydeera LR, Day B and Prather RS (2001) Partial inhibition of mitochondrial ATP production at the time of compaction improves development of in vitro produced porcine embryos Molecular Reproduction and Development 58 39-44

Maltepe E, Schmidt JV, Baunoch D, Bradfield CA and Simon MC (1997) Abnormal angiogenesis and responses to glucose and oxygen deprivation in mice lacking the protein ARNT Nature 386 403-407

Mercurio F and Manning AM (1999) Multiple signals converging on NF- $\kappa B$ Current Opinion in Cell Biology 11 226-232

Meyer M, Pahl HL and Baeuerle PA (1994) Regulation of the transcription factors NF-kappaB and AP-1 by redox changes Chemico Biological Interactions 91 91-100

Moley KH and Mueckler MM (2000) Glucose transport and apoptosis Apoptosis 5 99-105

Morales H, Tilquin P, Rees JF, Massip A, Dessy F and Van Langendonckt A (1999) Pyruvate prevents peroxide-induced injury of in vitro preimplantation bovine embryos Molecular Reproduction and Development 52 149-157

Munday R and Winterbourn CC (1989) Reduced glutathione in combination with superoxide dismutase as an important biological antioxidant defence mechanism Biochemical Pharmacology 38 4349-4352

Nasr-Esfahani MH, Aitken JR and Johnson MH (1990) Hydrogen peroxide levels in mouse oocytes and early cleavage stage embryos developed in vitro or in vivo. Development 109 501-507

Nasr-Esfahani MH, Winston NJ and Johnson MH (1992) Effects of glucose, glutamine, ethylenediaminetetra acetic acid and oxygen tension on the concentration of reactive oxygen species and on development of the mouse preimplantation embryos in vitro. Journal of Reproduction and Fertility 96 219-231

Nishikimi A, Mukai J and Yamada M (1999) Nuclear translocation of nuclear factor kappaB in early 1-cell mouse embryos Biology of Reproduction 60 1536-1541

Noda Y, Matsumoto H, Umaoka Y, Tatsumi K, Kishi J and Mori T (1991) Involvement of superoxide radicals in the mouse two-cell block Molecular Reproduction and Development 2 356-360

Nose K (2000) Role of reactive oxygen species in the regulation of physiological functions Biological Pharmacology Bulletin 23 897-903

Orsi $\mathbf{N}$ and Leese $\mathbf{H J}$ (2001) Protection against reactive oxygen species during mouse preimplantation embryo development: role of EDTA, oxygen tension, catalase, superoxide dismutase and pyruvate Molecular Reproduction and Development 59 44-53
Pantaleon M and Kaye PL (1998) Glucose transporters in preimplantation development Reviews of Reproduction 3 77-81

Pantaleon M, Ryan JP, Gil M and Kaye PL (2001) An unusual subcellular localization of GLUT1 and link with metabolism in oocytes and preimplantation mouse embryos Biology of Reproduction 64 1247-1254

Parrott JN and Gay NJ (1998) Expression and subcellular distribution of rel/NFkappaB transcription factors in the preimplantation mouse embryo: novel kappaB binding activities in the blastocyst stage embryo Zygote 6 249-260

Payne SR, Munday R and Thompson JG (1992) Addition of superoxide dismutase and catalase does not necessarily overcome developmental retardation of one-cell mouse embryos during in vitro culture Reproduction, Fertility and Development 4 167-174

Penzias AS, Rossi G, Gutmann JN, Haj-Hassan L, Leykin L and Diamond MP (1993) Dichloroacetic acid accelerates initial development of 2-cell murine embryos in vitro. Metabolism 42 1077-1080

Pierce GB, Parchment RE and Lewellyn AL (1991) Hydrogen peroxide as mediator of programmed cell death in the blastocysts Differentiation 46 181-186

Rozell MD, Williams JE and Butler JE (1992) Changes in concentration of adenosine triphosphate and adenosine diphosphate in individual preimplantation sheep embryos Biology of Reproduction 47 866-870

Schreck R and Baeuerle PA (1991) A role for oxygen radicals as second messengers Trends in Cell Biology $\mathbf{1} 39-42$

Semenza GL (1999) Regulation of mammalian $\mathrm{O}_{2}$ homeostasis by hypoxiainducible factor 1 Annual Reviews: Cell and Developmental Biology 15 $551-578$

Semenza GL (2000) HIF-1: mediator of physiological and pathophysiological responses to hypoxia Journal of Applied Physiology 88 1474-1480

Thomas M, Jain S, Kumar GP and Laloray M (1997) A programmed oxyradical burst causes hatching of mouse blastocysts Journal of Cell Science $1101597-1602$

Thompson JG, Simpson AC, Pugh PA, Donnelly PE and Tervit HR (1990) Effect of oxygen concentration on in vitro development of preimplantation sheep and cattle embryos Journal of Reproduction and Fertility $\mathbf{8 9}$ $573-578$

Thompson JG, Partridge RJ, Houghton FD, Cox CI and Leese HJ (1996) Oxygen uptake and carbohydrate metabolism by in vitro derived bovine embryos Journal of Reproduction and Fertility 106 299-306

Thompson JG, McNaughton C, Gasparrini B, McGowan LT and Tervit HR (2000) Effect of inhibitors and uncouplers of oxidative phosphorylation during compaction and blastulation of bovine embryos cultured in vitro. Journal of Reproducton and Fertility 118 47-55

Thomson JL (1967) Effects of inhibitors of carbohydrate metabolism on the development of preimplantation mouse embryos Experimental Cell Research 46 252-262

Tian H, Hammer RE, Matsumoto AM, Russell DW and McKnight SL (1998) The hypoxia-responsive transcription factor EPAS1 is essential for catecholamine homeostasis and protection against heart failure during embryonic development Genes and Development 12 3320-3324

Tscheudschilsuren G, Kuchenhoff A, Klonisch T, Tetens F and Fischer B (1999) Induction of arylhydrocarbon receptor expression in embryoblast cells of rabbit preimplantation blastocysts upon degredation of Rauber's polar trophoblast Toxicology and Applied Pharmacology 157 125-133

Wales RG (1975) Maturation of the mammalian embryo: biochemical aspects Biology of Reproduction 12 66-81

*Wenger RH (2000) Mammalian oxygen sensing, signalling and gene regulation Journal of Experimental Biology 203 1253-1263

Wenger RH and Gassman M (1999) HIF-1 and the molecular response to hypoxia in mammals. In Environmental Stress and Gene Regulation pp 25-45 Ed. KB Storey. BIOS Scientific Publishers Ltd, Oxford

Yao KS, Xanthoudakis S, Curran T and O'Dwyer PJ (1994) Activation of AP1 and nuclear redox factor, Ref-1, in response of HT29 colon cancer cells to hypoxia Molecular and Cellular Biology 14 5997-6003 